Revista Iberoamericana, Vol. LXXXI, Núm. 250, Enero-Marzo 2015, 161-182

\title{
LA LETRA Y EL CUERPO: LA IMAGEN VISUAL DE GABRIELA MISTRAL,
} 1905-1922

\author{
POR \\ Claudia Cabello \\ University of North Carolina, Greensboro
}

Cuando yo llegué a su presencia quise como hincarme pero ella me levantó rápidamente, me lo prohibió.

¿Por qué usted quiso hincarse frente a ella?

Fue un impulso irresistible. Como a un ser superior, pero ella me levantó.

¿Usted habia leido su obra?

No.

Isolina Barraza en conversación con Luis Vera, Gabriela del mundo

Mistral COMO ÍCONO

Gabriela Mistral, una mujer de un metro y ochenta centímetros de altura, rasgos indígenas, vestir franciscano, que no usaba joyas ni maquillaje, construye una imagen pública compleja y altamente funcional para su éxito como sujeto intelectual panamericano. La imagen pública de los escritores e intelectuales latinoamericanos en las primeras décadas del siglo veinte se crea y se pone en circulación por medio de mecanismos de difusión y recepción que involucran nuevas tecnologías y medios, sobre los que una escritora como Gabriela Mistral posee diversos grados de control. ${ }^{1}$ El explosivo crecimiento de la prensa, en conjunto con la importancia progresiva de la fotografía, abrió nuevas formas de difusión, circulación y representación tanto

\footnotetext{
' La definición de imagen pública para efectos de este análisis es amplia y parte de la definición de 'imagen': "Figura, representación, semejanza y apariencia de algo" e 'imagen pública': "Conjunto de rasgos que caracterizan ante la sociedad a una persona o entidad" (Diccionario RAE 1142). Si bien este 'conjunto de rasgos' está determinado por un sinnúmero de factores que a su vez varían individual e históricamente, en este trabajo me concentro en los que Mistral tiene un grado de agencia (fotografías, prácticas de difusión personal, performance público) y también los discursos y prácticas públicas de otros que al referirse a Mistral contribuyen a formar su imagen ante la sociedad.
} 
para la obra como para la imagen de los escritores. ${ }^{2}$ La imagen pública de Mistral es un producto -inestable y en permanente re-significación- que no está determinada únicamente por representaciones visuales, sino que mediante la interacción de textos literarios, testimonios, imágenes, discursos orales y prácticas simbólicas, que dan forma al ícono cultural que fue y es Gabriela Mistral. ${ }^{3}$

El corpus de las representaciones visuales de Mistral es enorme e incluye una multiplicidad de soportes y medios. Por ejemplo, astrónomos chilenos han visto su rostro en las estrellas -la Nébula NCG “Gabriela Mistral”- en la década de 1980, la dictadura militar decidió hacerla figurar en el billete chileno de cinco mil pesos; $y$, a través del tiempo, ha sido objeto de retratos, esculturas, estatuas, murales y estampillas, a lo que se suman miles de fotografías, algunas de las cuales presiden sobre salones de clases y bibliotecas a lo largo de Latinoamérica. ${ }^{4}$ La magnitud de este corpus, sus efectos culturales y también la renovada visibilidad de Mistral en Chile hoy, invitan a un estudio crítico que aborde la representación visual y las narrativas que contribuyeron a formar la imagen pública de esta escritora en función tanto de su propio proyecto literario, intelectual y político como de los usos que el Estado y otras instituciones le han dado. El presente trabajo propone un análisis del funcionamiento de la imagen de Gabriela Mistral, particularmente con relación a su proyecto intelectual en el espacio público latinoamericano de las primeras décadas del siglo xx, en el contexto de acercamientos teóricos y críticos que discuten la interacción de lo visual con el discurso cultural, la performatividad de género y la representación visual de la mujer. ${ }^{5}$

2 Sobre la historia de la prensa moderna en Chile ver, Carlos Ossandón y Eduardo Santa Cruz.

3 Existen muchos testimonios que describen la presencia física de Gabriela Mistral y que además sugieren lo problemática y desestabilizadora que esta resultaba. Palma Guillén, maestra mexicana y amiga de Mistral dice de su primer encuentro con ella en 1922: "A mí, que era una muchacha presumida, me pareció mal vestida, mal fajada, con sus faldas demasiado largas, sus zapatos bajos y sus cabellos recogidos en un nudo bajo" (vi). Pablo Neruda recuerda en sus memorias: "Pero cuando me llevaron a visitarla, la encontré buenamoza. En su rostro tostado en que la sangre india predominaba como en un bello cántaro araucano, sus dientes blanquísimos se mostraban en una sonrisa plena y generosa que iluminaba la habitación" (28).

4 En 2007 muere en Estados Unidos Doris Dana, compañera y albacea de Mistral. Tras un complejo y publicitado proceso, su sobrina, Doris Atkinson, decide donar el enorme archivo de Dana (165 cajas de materiales) al Estado de Chile. El legado sumó a las fotografías ya existentes, cinco nuevos álbumes con cientos de fotografías en su mayoría nunca antes vistas. Un libro que recopila una selección de estas fotografías ha sido publicado en Santiago de Chile bajo el título de Gabriela Mistral: álbum personal. Santiago: Pehuén Editores, 2008.

5 Los estudios de investigadores como Horan, Ana Pizarro (2005), Grínor Rojo (1997), Raquel Olea (1990), Soledad Falabella (2003) y Fiol-Matta (2001), entre otros, acerca de las narrativas y los mitos que buscaban explicar y promover ciertos aspectos de Mistral durante su vida, se insertan en un contexto de renovación de la crítica mistraliana que comenzó al final de la dictadura en Chile (1989) y que ha abierto un debate nutrido por teorías de género, subalternidad y los estudios culturales.

Revista Iberoamericana, Vol. LXXXI, Núm. 250, Enero-Marzo 2015, 161-182 ISSN 0034-9631 (Impreso)

ISSN 2154-4794 (Electrónico) 
La crítica e historia literaria se ha enfocado predominantemente en Gabriela Mistral como poeta, como la maestra de América dotada de las más altas virtudes morales $\mathrm{y}$, en menor medida, la ha destacado como una pensadora que dio visibilidad a los problemas del indio, la mujer y los derechos humanos en el continente. Sólo en las últimas dos décadas se ha comenzado a re-evaluar su pensamiento y agencia política, especialmente a través de sus textos en prosa. Mistral por su parte fomentó -a nivel discursivo y performativo- muchos de los mitos que crecieron en torno a ella y al igual que otras escritoras en ambientes intelectuales y creativos masculinos, contradijo en su práctica literaria e intelectual la pose de modestia y marginalidad que desplegaba, y que ahora reconocemos como "treta del débil" (Ludmer 1984). Se caracterizaba a sí misma como una mujer humilde, lejana a los círculos intelectuales académicos, así como una ganadora de premios y objeto de homenajes ‘inmerecidos' (el escritor Luis Enrique Délano recuerda que ella se refería al premio Nobel como ‘lo de Estocolmo’).

Las narrativas que trataron la biografía de Mistral tanto durante su vida como en las décadas posteriores a su muerte reforzaron los mitos que buscaban elevarla como la poeta dolorida, la maestra de América y la figura espiritual siempre virgen. Estas narrativas han sido descritas por Elizabeth Horan como "a nationalist adaptation of a hagiographic rethoric, permeated and shaped by overlapping critical anxieties about sexual and ethnic and racial identity" (Santa 27). De acuerdo a Horan, estas narraciones hagiográficas están dominadas por el pánico heterosexista que busca transformar la realidad de Mistral como mujer independiente, soltera y sin hijos biológicos mediante una definición caracterizada por su dedicación a la infancia y su canto a la maternidad. Este pánico, que persiste aun después de haber sido expuesto por un sector importante de la crítica, adquiere particular visibilidad, por ejemplo, en la prensa masiva, que desde la aparición del legado de su albacea, Doris Dana, ha dado espacio a voces y debates apanicados frente a la ya bastante 'comprobada' relación homosexual entre la escritora y Dana. ${ }^{6}$

Unárea de estudio todavía prácticamente inexplorada es la de la representación visual y la imagen pública de esta figura icónica. Mi investigación, entonces, se ha enfocado en la construcción de Mistral como sujeto intelectual, incorporando objetos y prácticas visuales en relación dialógica con textos, discursos y prácticas culturales. Conozco tres

\footnotetext{
6 A partir de los materiales de este archivo, como el recientemente publicado epistolario entre Mistral y Doris Dana, la identidad sexual de Mistral ha resurgido como tema de debate público. Si bien hay académicas y escritoras como Eliana Ortega, Diamela Eltit y Raquel Olea que han afirmado la productividad y necesidad de discutir abiertamente la identidad sexual de Mistral y la presencia de esta en su obra, hay muchos que aún asocian la afirmación de la heterosexualidad de Mistral con la defensa de su 'honor', su lugar en la historia literaria y en el imaginario nacional. Resulta emblemática de los límites a los que llegan quienes se niegan a cuestionar la identidad heterosexual de Mistral la declaración del crítico literario Camilo Marks al diario Las Últimas Noticias: "Ella era profundamente heterosexual" (26 de octubre 2007).
}

Revista Iberoamericana, Vol. LXXXI, Núm. 250, Enero-Marzo 2015, $161-182$ ISSN 0034-9631 (Impreso) ISSN 2154-4794 (Electrónico) 
trabajos dedicados exclusivamente al análisis de la imagen visual de Gabriela Mistral y todos muestran de manera provocadora el enorme potencial que el plano de lo visual tiene en el contexto de renovación de la crítica mistraliana. ${ }^{7}$ Sin embargo, muy poco se ha analizado la imagen de Mistral entre 1905 a 1922, concentrándose la atención más bien en el periodo posterior a su salida definitiva de Chile (1922) y más allá de su muerte. Es fundamental acercarse a las primeras dos décadas de su formación e internacionalización donde se encuentran los orígenes de una vida pública y literaria que se sostiene en parte gracias a una cuidadosa y compleja auto-representación tanto a través de la letra como del cuerpo.

Mi intención es, por lo tanto, poner en evidencia que la imagen pública de Mistral y el manejo que ella hace de ésta desde sus comienzos juega un rol fundamental en el lugar e influencia que esta figura tuvo en la historia cultural chilena y latinoamericana de la primera mitad del siglo xx. ${ }^{8}$ La pregunta que me guía es hasta qué punto la escritora, en el período que va desde 1905 hasta 1922 manifiesta en el plano visual una voluntad de construirse como sujeto intelectual panamericano y cuáles son las estrategias que pone en práctica en términos de su representación visual. Al mismo tiempo, resulta central tanto para este análisis como para entrar en un debate crítico más amplio preguntarse en qué medida su imagen adhiere a la normativa de género y clase social de la época o si exhibe un poder desestabilizador para estas categorías de identidad. Finalmente, en un intento por incluir nuevos elementos de análisis que permitan ampliar y complejizar la comprensión de la imagen de Mistral desde su recepción, he considerado un conjunto de textos de escritores de la época para establecer los vínculos entre la imagen que estos textos presentan y las imágenes de sí misma que Mistral promueve a nivel discursivo y visual.

Junto a cuestiones centrales como la representación visual y la circulación de la imagen del intelectual, es necesario abordar el 'problema' de la auto representación de género, en medio de un contexto histórico en el que ser mujer es incompatible con las ambiciones intelectuales y de figuración pública de mujeres como Mistral. Vicky Unruh, en Women and Modern Literary Culture in Latin America: Intervening Acts estudia la imagen pública y el performance de escritoras contemporáneas a Mistral y propone que el acceso de estas mujeres al mundo artístico se derivó en gran parte de su performance público donde fueron capaces de poner en escena su trabajo intelectual

\footnotetext{
Ver, Licia Fiol-Matta, "Image is everything" en A Queer Mother for the Nation: the State and Gabriela Mistral (2002), Elizabeth Rosa Horan, "Santa Maestra Muerta: Body and Nation in Portraits of Gabriela Mistral" (1997) y María de la Luz Hurtado, "La performance de los Juegos Florales de 1914 y la inadecuada presencia de Gabriela Mistral en ellos" (2008).

8 No es mi intención negar el talento literario excepcional de Mistral; sin embargo, al examinar otros aspectos y textos - prosa periodística, discursos, cartas, labor pedagógica- es posible afirmar que el trabajo en muchos frentes (prensa-poesía-estado) es fundamental en el éxito literario, la internacionalización y la participación de Mistral en las redes de pensamiento más importantes de la primera mitad del siglo xx.
}

Revista Iberoamericana, Vol. LXXXI, Núm. 250, Enero-Marzo 2015, 161-182 
y su talento. ${ }^{9}$ La figura de Mistral como escritora, su imagen, su performance no está aislada de su obra ni menos aún de su biografía, son hebras de un complejo tejido que constituyen su imagen pública. ${ }^{10}$ Esta a su vez tiene consecuencias en el imaginario que va construyéndose en torno a ella, y que provoca reacciones como el que grafica el testimonio de Isolina Barraza citado al comienzo de este trabajo donde una mujer de pueblo que no ha leído la obra de Mistral reacciona ante su presencia como si estuviera delante de un dignatario o figura religiosa. Este testimonio revela además que la imagen de Mistral transita por diversos estratos sociales y que tiene efectos en un sector popular a veces lejano al público lector. Otros hechos históricos, como por ejemplo, las multitudinarias ceremonias que en 1922 despiden a Mistral antes de su viaje a México, sirven para calibrar la visibilidad pública de la escritora, excepcional para una mujer en las primeras décadas del siglo Xx.

A pesar de la escasa atención crítica a la imagen visual de Mistral, resulta un tema ineludible si se toma en consideración el interés y el debate que generaba la presencia física de Mistral desde el comienzo de su carrera literaria. Aun cuando no fue un objeto de estudio en sí mismo, mucho se habló y escribió sobre la presencia física de la escritora, y hay testimonios e interpretaciones sugerentes que entregan claves de entrada al asunto. Fernando Alegría, comienza su libro Genio y Figura de Gabriela Mistral (1966) relatando la impresión le causó su primer encuentro con la escritora. Allí también da testimonio del efecto que Mistral generaba y explica la atracción que ejercía sobre las personas, "que iban hacia ella como quien entra a una iglesia" (14). Para Alegría, estas reacciones eran el resultado de que la presencia de Mistral permitía adivinar que 'le había sido revelada la verdad primera':

\begin{abstract}
Algunos seres nos indican por su presencia que la conocen [la verdad primera] ...Algunos místicos, especialmente los poéticos deciden entonces escribir en su presencia física los signos del más allá que ellos conocen. De ahí nace una actitud especial; podemos llamarla pose sin intentar menoscabo y esta actitud debe ser eternamente cultivada. La influencia de esta pose es grandiosa. Mueve a las multitudes y transforma a los individuos. En casos como el de Gabriela Mistral, esa actitud llegó a ser una fuerza social de ímpetu admirable (14; énfasis mío).
\end{abstract}

\footnotetext{
9 Unruh explica el poder del performance público de estas escritoras: "performance activity-even when it shored up gender norms in the face of change-provided these women a far richer repertoire and more malleable site for negotiating their art of living as intellectuals than did reigning models of women's writing, embodied for example in the poetisa"(16).

${ }^{10}$ La idea de performance con que trabajo está basada en la teoría de Butler acerca de la performatividad de identidad y género como actos repetitivos que constituyen determinda identidad y que a su vez encierran la posibilidad de subversión y desestabilización de la misma (Butler 1990; 1993). En un sentido más amplio entiendo performance, a partir de las ideas de Diamond (1996), siempre en relación con las historias culturales, las tradiciones y las respuestas políticas que componen el sentido de la historia.
}

Revista Iberoamericana, Vol. LXXXI, Núm. 250, Enero-Marzo 2015, 161-182 ISSN 0034-9631 (Impreso)

ISSN 2154-4794 (Electrónico) 
Ese 'escribir en su presencia física' al que se refiere Alegría (quien sin embargo no dedica más líneas al asunto en el libro), junto con la lectura de esa 'pose', la aludida 'fuerza social' y el poder para mover multitudes, es lo que a mi juicio invita al estudio de la imagen pública de Mistral, particularmente en su etapa de formación y temprana internacionalización. Este como otros testimonios reflejan hasta qué punto Mistral logró a nivel visual y performativo ser percibida como un sujeto que entendía y veía más allá que el resto de la gente. Esta perspectiva privilegiada de la escritora le permitía revelar una verdad oculta a los ojos de los demás. La imagen de Mistral como un sujeto excepcional es fundamental para entender su éxito en el acceso a ciertos circuitos intelectuales y creativos. ${ }^{11}$

Hay otras razones que exigen una lectura de la imagen-en realidad de las imágenes-de Mistral, particularmente a la luz del dominio de lo visual que caracteriza a la modernidad. En primer lugar, en el contexto histórico y cultural en que se desarrolla la carrera literaria y profesional de Mistral, la imagen de una figura pública y su reproducción en distintos medios se transformó rápidamente en un hecho ineludible y altamente deseado por el creciente público consumidor de medios de prensa y de tecnologías visuales en proceso de masificación. En segundo lugar, el corpus que componen las representaciones visuales de Mistral es enorme y la circulación que tuvieron y todavía tienen algunas de estas imágenes es continental. Los chilenos, por ejemplo, como consecuencia de su presencia en el billete emitido en los 1980's y en otros lugares, identifican inmediatamente su rostro al mismo tiempo que reconocen haber leído poco o nada de su obra. Finalmente, la relación entre la performatividad de género y el poder, que se quiere evocar o confrontar a nivel visual, explica ciertos aspectos del proceso que transforma a Lucila Godoy Alcayaga, la maestra del Valle del Elqui, en el ícono panamericano que es Gabriela Mistral.

La teoría visual aporta ideas y conceptos esenciales a este análisis, particularmente en términos de la relación entre la imagen y el discurso. W.J.T. Mitchell en Teoría de la imagen presenta la idea del giro pictorial como "un redescubrimiento poslinguístico de la imagen como un complejo juego entre la visualidad, los aparatos, las instituciones, los discursos, los cuerpos y la figuralidad" (23). Esta perspectiva, junto a la teoría de género, resultan productivas para examinar críticamente a una figura icónica como Mistral, que se relacionó visual, física y textualmente con distintos sujetos e instituciones, poniendo

11 Zygmut Bauman sostiene la separación entre lo que define a los auto-definidos intelectuales con los demás es la razón de ser del ejercicio de definirse y no su efecto (Bauman 8). Si bien Mistral declara en varias ocasiones que ella no es una intelectual y que no aspira a serlo (al menos el tipo de intelectual que ella busca criticar públicamente: masculino, de clase alta, lejano de la clase obrera), su imagen, como se verá, facilita el que ella ocupe un lugar y una función en la sociedad que corresponde al lugar del intelectual. El modo en que ella redefine el concepto y la práctica del intelectual en su época queda fuera del marco del presente ensayo.

Revista Iberoamericana, Vol. LXXXI, Núm. 250, Enero-Marzo 2015, 161-182 ISSN 0034-9631 (Impreso)

ISSN 2154-4794 (Electrónico) 
en juego identidades de género, raciales y sociales complejas. Si bien como señala Mitchell el discurso está limitado para traducir o representar lo visual en su complejidad, me parece que es posible concentrarse no solo en la imagen misma sino en sus efectos culturales. Efectos que dan cuenta del poder de las imágenes, en su capacidad de evocar sentimientos, ideas y provocar reacciones. La profusión de discursos que intentan fijar, definir y regularizar la imagen de Mistral -tanto en vida como después-así como la persistencia con que aparece asociada su imagen al Estado y otras instituciones son testimonio de este poder.

Uno de los argumentos centrales de Mitchell en Iconology es renunciar a la aspiración de una teoría científica de lo visual y permitir el encuentro del ícono con el logos: "This move, in my view, takes iconology well beyond the comparative study of the verbal and visual art and into the basic construction of the human subjects a being constituted by both language and imaging" (24). Esta idea puesta en el contexto de la modernidad latinoamericana y la centralidad de lo visual que la caracteriza, pone de relieve la utilidad de estudiar la imagen de Mistral si se quiere definir con mayor precisión su lugar en la historia intelectual y literaria.

\section{Madre y amante dolorida, ¿'Más allá de los SeXos’?}

Consciente de la imposibilidad de una análisis exhaustivo del tema me interesa esbozar algunos aspectos centrales de la imagen pública de Mistral durante el período chileno para explicar, al menos en parte, el proceso mediante el cual Lucila Godoy Alcayaga llega a ser en 1922, Gabriela Mistral, educadora invitada por el gobierno de México, poeta autora de Desolación, figura popular y controversial.

En A Queer Mother for the Nation: the State and Gabriela Mistral, Fiol-Matta analiza brevemente esta etapa de formación y trabaja a partir de la hipótesis de que Mistral fue extraordinariamente exitosa con su imagen de 'la Madre', aun cuando era descrita al mismo tiempo en términos masculinos, adoptando incluso un estilo de vestir masculino o masculinizador en comparación con sus contemporáneas. Fiol-Matta por medio de un análisis de fotografías de Mistral y de otras representaciones de lo femenino en la prensa busca demostrar cómo la rareza, el queerness de Mistral fue puesto a trabajar para el Estado que manipula su iconografía en torno a la imagen de 'la madre'. Fiol-Matta plantea que los cambios de su imagen demuestran que ella probó distintas versiones de sí misma, algunas de ellas de acuerdo a los estándares de fotografía de la época (125) lo que significaría que Mistral no parecía segura de cómo promoverse públicamente en esta primera etapa. ${ }^{12} \mathrm{Si}$ bien concuerdo en varios de los puntos con

12 "The young Mistral was uncertain about how to promote herself publicly, both in print and visually" (Fiol-Matta 130).

Revista Iberoamericana, Vol. LXXXI, Núm. 250, Enero-Marzo 2015, $161-182$ ISSN 0034-9631 (Impreso)

ISSN 2154-4794 (Electrónico) 
Fiol-Matta, creo que es posible sostener, a la luz de un corpus más amplio, que Mistral trabajó su imagen pública desde sus comienzos de forma estratégica con el objetivo de alcanzar reconocimiento intelectual y acceder a ciertos circuitos de producción cultural. Fiol-Matta afirma a su vez que Mistral pasa de una imagen temprana muy prototípica de mujer soltera, con poses indudablemente femeninas hacia una imagen explícitamente más butch. Con esto intenta probar que mientras más masculinizó su imagen en el campo visual, se hizo cada vez más parte de las proyectos del Estado y su propaganda (127). Los primeros retratos de Mistral sí presentan una imagen culturalmente más femenina, pero para comprender la construcción de su figura, el manejo estratégico de su imagen con relación a identidades de género, clase y raza deben considerarse al menos dos elementos más. Primero, al incorporar los textos tanto de Mistral como de otras figuras públicas de la época, la imagen en su sentido más amplio se complejiza. Segundo, al considerar otras prácticas por las que se construye y circula la imagen de Mistral -retratos firmados, cartas, intervenciones en debates públicos- se hace más clara su voluntad de hacer uso de su imagen en pos de su proyecto creativo, intelectual y político. La figuración pública de Mistral desde 1905, en un principio exclusivamente a través de la letra impresa, revela su intención de construirse como mujer escritora, pensadora y promotora de políticas públicas por medio de estrategias retóricas, visuales y performáticas que exhiben al mismo tiempo que desbordan y trascienden las identidades de género y clase (el manejo de la identidad racial como lo explica Fiol-Matta se hace más evidente a partir de su estadía en México). Mistral se afirma en esas identidades y al mismo tiempo las re-significa, evitando así que se la circunscriba a categorías que la excluyen de los circuitos intelectuales y plataformas discursivas en las que, con dificultad, comienza a ingresar.

Ya en sus primeros textos literarios de tono subjetivo y testimonial, como lo son sus prosas poéticas del tipo "Carta íntima"(1905), "Espejo roto" (1905) o "Páginas de un libro íntimo" (1906), todas firmadas por Lucila Godoy o Alguien, Mistral va sentando las bases de los mitos en torno a ella, mitos que se irán imprimiendo progresivamente en su imagen y permearán los discursos de otros cuando la describan. Una idea persistente que los discursos de escritores, críticos y periodistas acerca de Mistral ponen en circulación es la imagen romántica y al mismo tiempo semi-religiosa de una mujer entregada al arte y al conocimiento. Este ideal de artista, que renuncia a los bienes materiales y, particularmente en el caso de la mujer, a la vanidad, será reforzado en adelante por Mistral, quien tanto en cartas personales como en prosa periodística, opondrá la intelectualidad a la vanidad de la mujer. La oposición que Mistral establece entre conocimiento y vanidad en la mujer aparece ya en 1906, en una de sus primeras publicaciones, titulada "Instrucción de la mujer" donde llama a quienes deciden acerca de la educación femenina, "Hágasele amar la ciencia más que las joyas y las sedas" (Recopilación 99). El efecto de esta idea resuena en los comentarios del crítico literario, Carlos Soto Ayala, quien

Revista Iberoamericana, Vol. LXXXI, Núm. 250, Enero-Marzo 2015, $161-182$ ISSN 0034-9631 (Impreso) 
en Literatura Coquimbana, la primera antología en incluir textos de Mistral de 1908, destaca a la escritora como una de las pocas mujeres que prefiere ser reconocida por su talento que por su belleza o linaje. Se refiere a ella como "La inteligente prosista" (Soto Ayala 101) y haciendo eco de su pose romántica señala, "La señorita Godoi es un Lamartine femenino; es un Bécker con alma de mujer (ortografía original 103). En Literatura Coquimbana la descripción de la escritora y su obra recogen las ideas que la misma Mistral ha sembrado acerca de su persona, sus ambiciones e ideales estéticos, lo que resulta en la construcción de una imagen de una joven escritora en la que se destaca públicamente su talento literario, intelectualidad y precocidad. Soto Ayala es también el primero en describir a Mistral como un sujeto extraordinario, diferente del resto, por medio de comentarios tales como: "es tan hermoso a la par que interesante estudiar el alma de los elejidos" (ortografía y énfasis original 101). Este será uno de los tópicos que se reiteran incansablemente en los comentarios a su figura a lo largo de su vida, y más aún después de su muerte. Por otra parte, las primeras prosas poéticas, cuentos y crónicas que Mistral publica en periódicos locales y que la dan a conocer en la región de Coquimbo, promueven una imagen de la poeta como una joven sombría y amargada. Los temas de sus primeros cuentos y prosas poéticas: muerte, soledad, amor, enfermedad y locura, hacen a sus lectores fantasear respecto de la autora y su situación personal, por ejemplo, en el caso del mismo Soto Ayala quien supone que "esas pájinas están escritas en el santuario de la soledad, egoísmo enfermo de dolor" (orografía original 104). Ahí estaría el origen de Mistral como la escritora dolorida, mito que más tarde ella querrá matizar al destacar otros tópicos de su poesía y labor profesional. ${ }^{13}$

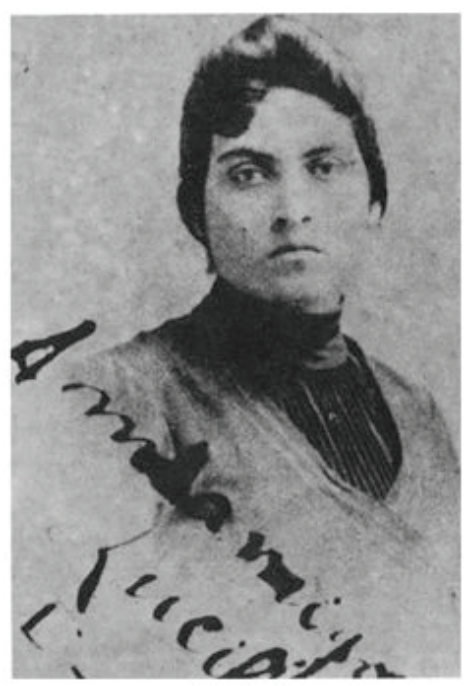

Figura1

Una de las pocas fotografías que existen de esta etapa, antes de su traslado a la zona central de Chile, es un retrato de 1906, dedicado al pintor y pianista Alfredo Videla Pineda (fig.

13 En 1924 Mistral declara: "yo ya no quiero hacer más poesía dolorosa. [...] Ya es tiempo de aquietarse, de serenarse, se encienden lámparas, el agua tiene un color de paz y si yo persisto en ese actitud parecerá que es 'pose', y yo detesto la 'pose'; por eso me enfada que se me quiera retratar con un libro en la mano o escribiendo" (García Huidobro 88). Mistral quiere controlar su imagen pública y usa la tribuna que le da esta entrevista para declarar públicamente que ella no quiere 'posar' como intelectual o como poeta dolorida.

Revista Iberoamericana,
Vol. 
1). ${ }^{14}$ Este, al mismo tiempo que da cuenta de una imagen de Mistral más conforme al estereotipo cultural femenino, es un testimonio de su práctica temprana de regalar retratos autografiados. El retrato dice: "A mi amigo Alfredo, Lucila". Aunque con este hombre Mistral mantuvo una correspondencia amorosa en el contexto de una relación aparentemente platónica, la costumbre de regalar retratos persistirá con fuerza. ${ }^{15} \mathrm{Me}$ detengo en este gesto, ya que Videla Pineda era a la vez, un hombre que gozaba de una cómoda situación económica y era un actor de la vida cultural de la provincia, al que Mistral llega a conocer por carta. Mistral tenía la costumbre de escribir a cualquier persona que le interesara, desde un escritor emergente hasta Rubén Darío, a quien escribe en 1912. Esta estrategia, que la lleva a establecer lazos profesionales y de amistad es reveladora no solo de su curiosidad intelectual y de una búsqueda de diálogo, sino también de su deseo de ser reconocida por estos sujetos, muchos de los cuales integrarán el canon de la historia cultural chilena y latinoamericana. El hecho concreto de incluir un retrato junto con sus cartas sin duda promueve una imagen más completa y memorable para el receptor junto con darle un tono más personal y cercano a una comunicación, que en la mayoría de los casos es a distancia.

Respecto de este retrato en particular, y haciendo una breve lectura semiótica a partir de otros retratos de la época es importante resaltar que la expresión seria y la mirada desviada del retratado eran rasgos típicos de las fotografías de mujeres en este período. Creo, sin embargo, que la severidad de la mirada de Mistral es particularmente acentuada y es característica de otros retratos posteriores en los que posa en su rol de maestra o directora de escuela, y parecen querer evocar la autoridad e imposición de disciplina que se exigía a las maestras. Es posible interpretar esta seriedad y sencillez en las poses como un mecanismo que por otro lado evita una pose sentimental o genéricamente marcada como la que se encuentra, por ejemplo, en la reina de los Juegos Florales de Santiago (fig. 2). ${ }^{16}$

${ }_{14}$ La correspondencia entre Mistral y Videla Pineda que conocemos data de 1905 y 1906. Está publicada en Cartas de amor de Gabriela Mistral.

${ }_{15}$ En el archivo de Mistral, recientemente donado al gobierno de Chile, existen varios sobres que contienen decenas de retratos autografiados, que Mistral tenía para regalar a la mucha gente que la visitaba. Hay también en este archivo innumerables cartas, tanto de personas desconocidas como de escritores, en que le piden a Mistral que envíe un retrato dedicado.

${ }^{16}$ Mistral ganó la flor natural con su poema "Los sonetos de la muerte" y María Letelier del Campo fue coronada Reina lo que obligaba a Mistral a escribir un poema en alabanza de su belleza. Como es sabido Mistral no asistió a la premiación. Para un análisis detallado del performance en los Juegos Florales de 1914, ver el excelente artículo de María de la Luz Hurtado.

Revista Iberoamericana, Vol. LXXXI, Núm. 250, Enero-Marzo 2015, 161-182 ISSN 0034-9631 (Impreso)

ISSN 2154-4794 (Electrónico) 
Esta imagen al mismo tiempo que representa un ideal femenino de la época, premiado, por lo tanto, en el evento cultural y social más importante del año, hace evidente que la moda y en general la imagen femenina tiene relación directa con un tema de clase social. La minimalización de los símbolos de la feminidad de la época: sombreros, maquillaje, joyas, que revelan las fotografías de Mistral, es más evidente al comparársela con esta mujer y con las mujeres de la corte de amor de los Juegos Florales, todas señoritas de clase alta que ostentan un exceso de adornos, pieles y peinados. De todos modos, aun comparada

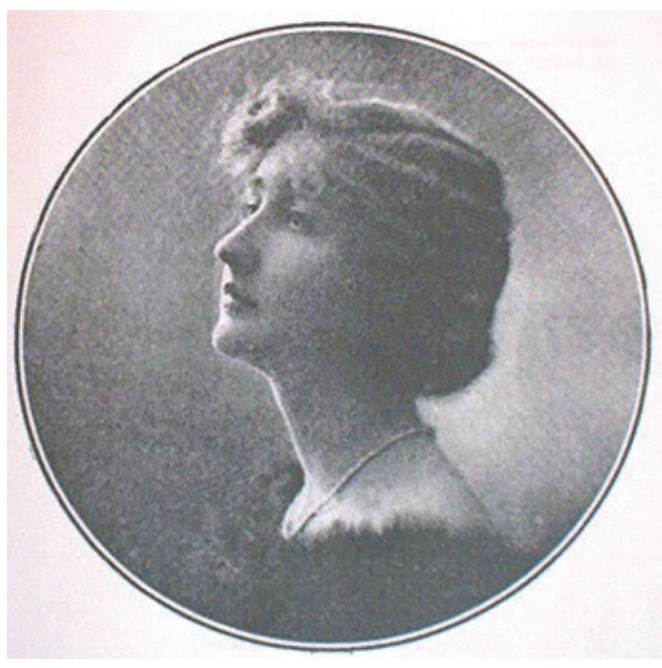

Figura 2 con otras maestras, Mistral exhibe, sobre todo desde los años 1920 en adelante una pose más rebelde ante el modelo de femineidad dominante que sus compañeras (Fig. 3). ${ }^{17}$ Fotografías y testimonios de la época desacreditan la idea de que ella se veía como cualquier profesora de provincia, o que su modo o trato eran comunes. Inés Echeverría (Iris) escritora contemporánea a Mistral, que se relacionó con ella a pesar de las grandes diferencias de clase que las separaban hace una larga descripción de Mistral donde la pone en una categoría más allá de lo femenino y masculino: "Junto a la potencia de un guerrero aborigen, el gemido de una mujer irredenta. Trasciende bravura y nostalgia. Está más allá de los sexos. Palpita en su ser el alma colectiva y potente de la tribu" (523). Para Iris Mistral estaría más allá de los sexos no solo por la austeridad y el hecho que Mistral "se mostraba al desnudo implacable de la naturaleza"(524), es decir, no se maquillaba, ni peinaba sofisticadamente, sino por ser un sujeto cuya fuerza y singularidad no calza en los esquemas de clase y género de su tiempo. Este testimonio que aporta la mirada de una mujer ante Mistral contribuye al presente análisis en tanto no explica la 'rareza' de Mistral en términos simples de una mujer masculina sino que abre posibilidades identitarias 'más allá de

${ }^{17}$ Si bien la crítica y yo misma me he referido a la imagen 'masculina' de Mistral, me parece necesario advertir que su no conformación con una imagen estereotípicamente femenina no es necesarimente sinónimo de una imagen masculina. Más bien puede leerse alternativamente como un acto que desafía las convenciones dentro de las cuales una sociedad patriarcal define lo femenino y lo inscribe en el cuerpo de la mujer.

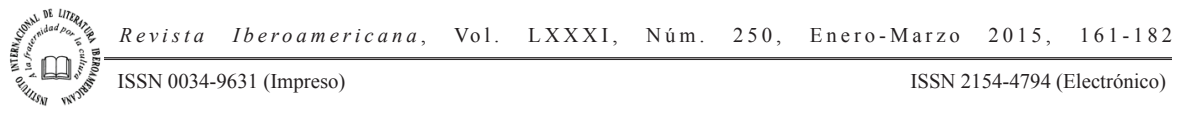


los sexos'. La imagen de Mistral entonces, en su sentido más amplio, tuvo (y debe tener) como uno de sus efectos hacer evidente las estrechas definiciones de género de su época y su relación con la intelectualidad, al borrar de una manera no explícitamente confrontacional, pero indiscutible, los límites de género, de clase y de raza. ${ }^{18}$

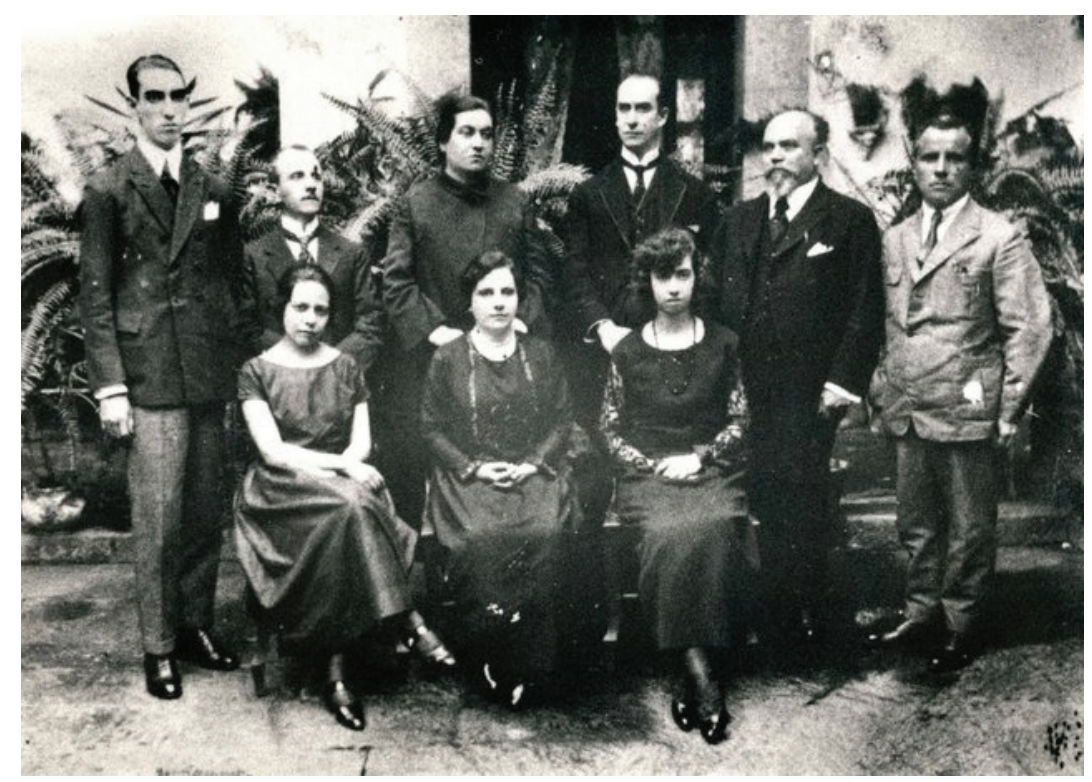

Figura 3

\section{LA INTELECTUAL EN CUERPO DE MUJER}

La categoría de género sexual y por tanto la teoría de género resultan esenciales en este análisis de la imagen pública y el performance de Mistral. La teoría feminista contemporánea entrega algunas herramientas básicas para enfrentarse a la representación

${ }^{18}$ Un ejemplo de cómo la presencia de Mistral en esferas hasta entonces consideradas masculinas hace visible lo arbitrario e inadecuado del concepto decimonónico 'hombre de letras' como sinónimo de intelectual es la siguiente afirmación de Pedro Henríquez Ureña: "The men of letters-literature not being really a profession, but an avocation-became journalists or teachers or both. [...] Some obtained diplomatic or consular posts; the custom is maintained to this day, and it includes women now, such as the Chileans Gabriela Mistral and Marta Brunet, the Cuban Flora Díaz Parrado and the Colombian Laura Victoria" (Henríquez Ureña 161).

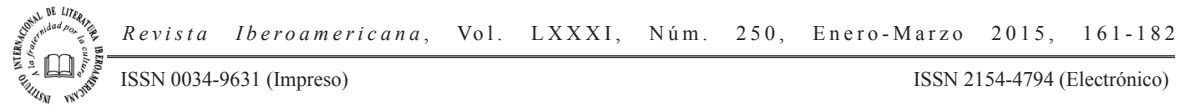


de la mujer, su relación con el poder y la esfera pública, siendo una de ellas la idea de que el género es una construcción cultural (Judith Butler). La definición del término mujer es inestable y como toda identidad no es unitaria ni coherente, como explica Butler: "woman itself is a term in process, a becoming, a constructing that cannot ritghfully be said to originate or to end. As an ongoing discursive practice, it is open to intervention and resignification" (Gender 33). Entonces, cuando identificamos a Mistral en esta etapa con una pose más 'femenina', es a partir de un estudio de los parámetros de la feminidad de la época, ya que para Butler el sexo de cada cual solo puede ser reconocido en tanto asuma las características sociales aprobadas (Bodies 14).

Otro hecho a considerar es que la imagen de la mujer y su relación con el espectador y consigo misma es diferente que la del hombre. Los planteamientos de John Berger en Modos de ver resultan claves para dimensionar estas diferencias. La hipótesis de la que parte Berger es que la presencia social de la mujer es distinta que la del hombre, porque la presencia del hombre encarna una promesa de poder, que es un objeto siempre exterior a él, ya sea esta moral, física o económica. En cambio, “a woman's presence expresses her own attitude to herself, and defines what can or cannot be done to her. Her presence is manifest in her gestures, voice, opinions, expressions, clothes, chosen surroundings, taste - indeed there is nothing she can do which does not contribute to her presence" y más adelante Berger agrega, "She has to survey everything she is and everything she does because how she appears to others, and ultimately how she appears to men, is of crucial importance for what is normally thought of as the success of her life" (54). Todo lo que hace, dice y expresa Lucila Godoy en su proceso de construcción como escritora y maestra juega un papel en este proceso. Sus contemporáneos leyeron y significaron su performance a partir de los códigos de género, de clase y de raza de su tiempo y la crítica ahora puede leer tanto el performance de Mistral como esas lecturas de su tiempo. A partir de estas ideas es posible ver hasta qué punto Mistral trabajó por minimizar los aspectos, gestos, símbolos que la asociaban con identidades que obstaculizaban su desarrollo como escritora e intelectual, y como refuerza, por otro lado, los que le favorecían. Una de las consecuencias de esta manipulación de su imagen es la mencionada borradura de los límites que separan, por ejemplo, las identidades hombre y mujer, y es una de las razones por la que su imagen fuera percibida como 'rara'.

En el contexto de los desafíos que implica la representación de la mujer en el arte, Rosemary Betterton, entrega claves importantes que iluminan el complejo proceso de auto-representación de la mujer:

Women have always been visible as objects within culture, but only rarely have they been acknowledged as subjects of cultural production in their own right [...] This makes any attempt by women to represent themselves doubly difficult. It demands a continuing movement between the criticism of existing imagery and the creation of new kinds of representation for women. Nowhere is this more important than when

Revista Iberoamericana, Vol. LXXXI, Núm. 250, Enero-Marzo 2015, 161-182 ISSN 0034-9631 (Impreso)

ISSN 2154-4794 (Electrónico) 
women intervene to change the conventions by which femininity is circumscribed and mapped out on the female body (203).

Las imágenes y los textos de Mistral durante esta etapa chilena dan cuenta de su visión crítica frente a la representaciones estereotípicas de la feminidad de ese momento. Si bien ella no parece querer promover un cambio general, sí es posible ver en su propio performance, en su resistencia a encarnar una feminidad 'tradicional', un intento por probar una nueva forma de representación, que como identifica Betterton, cambie las convenciones por medio de las cuales la feminidad se inscribe en el cuerpo de la mujer. Es por eso que me resisto a seguir identificando la imagen pública de Mistral como masculinizada, porque esto le quita el valor subversivo al gesto mistraliano.

En Mistral, la intervención de las convenciones por las cuales la feminidad se traza y encarna en el cuerpo de la mujer es lo que está en juego en la imagen exitosa de una 'Madre' que no es ni madre biológica ni performativamente femenina. Resulta contradictorio también que la identificación, aunque espiritual, con la función biológica del cuerpo de la mujer, ser madre, este presente en el caso de Mistral de la mano de su lugar excepcional en la producción de la cultura. Sin embargo, como apunta Fiol-Matta el discurso que promueve a Mistral como la 'Madre' viene más bien del estado y no de los discursos de intelectuales y escritores contemporáneos que permiten entender los elementos claves de su imagen y performance que son funcionales a su rol de intelectual y que permiten su entrada y participación en las esferas de poder cultural y político. Si bien hubo quienes rechazaron a Mistral y castigaron su 'diferencia' hay numerosos testimonios que sugieren que su imagen tuvo un rol en su éxito como intelectual. Es posible sugerir, en términos de Berger, que la presencia de Mistral sobre todo hacia el final de su etapa chilena será cada vez menos acerca de su imagen (como en el caso de la mujer) y más acerca de su poder cultural, su identificación con la nación y su capacidad de convocatoria.

La inteligencia excepcional, la genialidad, es un tópico constante en las descripciones que se hacen de Mistral. Muchas veces esta se mezcla con la identificación de la poeta como una figura mística, otro tema central. Mistral es percibida como fuera de las categorías en las que cae el común de la gente, un cronista de la época dice: "Fuera del mono de Juan Duval, todos los que conocen a Gabriela, la sienten aureolada por facultades casi únicas" (en Mistral Recopilación 482). Ana Michelet, en una crónica publicada de 1913 en el periódico "La Mañana" de la localidad de Los Andes la describe en los siguientes términos: "una joven de cuerpo elevado, de rostro suavemente sonrosado, frente llena de nobleza espiritual, grandes ojos celestes que miran con esa bondad grave y tierna, de las hermanas de la caridad. Creía estar contemplando, en su serena austeridad a una religiosa que recién hubiera despojado a su cabeza de la toca" (Michelet 181). Aquí Michelet aplica una práctica retórica que la misma Mistral emplea en sus descripciones de otras figuras públicas al vincular los rasgos físicos, la estampa del sujeto, con sus

Revista Iberoamericana, Vol. LXXXI, Núm. 250, Enero-Marzo 2015, 161-182 ISSN 0034-9631 (Impreso)

ISSN 2154-4794 (Electrónico) 
características psicológicas e intelectuales como si tuvieran una relación de causalidad. Michelet da un cuerpo a Mistral que no cae dentro de una identidad mujer o hombre, sino en una categoría excepcional, la de religiosa, un sujeto que con la aprobación social y por su función mística vive fuera de esas normas en tanto no amenaza directamente los códigos sexuales pues se entiende que no 'funciona' en esos términos.

Esta imagen de Mistral como una figura religiosa y asexuada ha sido también problematizada y revisada por la crítica contemporánea, y más allá de si se puede interpretar su figura como asexuada o no, que es algo que se hizo sobre todo hasta finales de los años ochenta en Chile, interesan los efectos de ese aspecto de su imagen pública durante su vida. Es evidente que la descripción de Michelet promueve una imagen de Mistral muy diferente a la de las feministas u otras mujeres de visibilidad pública en ese momento (1913), mujeres jóvenes, modernas, con un estilo 'garçonne'y que representaban en las calles y revistas la fuerza del cambio en cuanto al lugar de las mujeres y sus derechos. ${ }^{19}$ La imagen de Mistral y también su discurso no se identifica con la imagen de la mujer moderna o de la sufragista de comienzos del siglo xx. Su imagen se ubica en un lugar aparentemente menos amenazador, más único y por lo tanto, más inasible. La idea de la maestra/escritora como una religiosa o una madre sin duda familiariza su imagen y la acerca a las normativas genérico-sexuales de la época.

Volviendo a sus comienzos como figura pública, me interesa examinar el propósito de Mistral de alejar a la mujer (en tanto objeto sexual y estereotipo negativo) de la escritora, idea que nace muy temprano en ella y se relaciona directamente con el manejo de su imagen. En 1911, mientras se halla la ciudad de Antofagasta, Mistral reflexiona acerca de ciertas dificultades sociales que experimenta: "Noto que no tengo condiciones para ganarme la cordialidad fácil de la gente que me rodea. $\mathrm{O}$ me profesan una veneración que no me agrada o me demuestran desconfianza o cierta dolorosa frialdad" (citada en Teitelboim 56). Resulta notable la explicación que ella se da y la fragmentación de la identidad que aquí se manifiesta: "Capaz que todo esto se deba a que todo en mi vida tiene un fondo intelectual. Primero soy eso y después, pero muy después recién soy mujer sin mucha gracia humana y sin mucha comunicación" (citada en Teitelboim 56). Mistral traza una división entre dos elementos constitutivos de su identidad, organizados a su vez jerárquicamente: el ser intelectual determina su carácter y podemos asumir su imagen mientras la identidad de género sexual está relegada, o más bien perturbada

19 Después de su salida de Chile Mistral escribe una carta a Rafael Heliodoro Valle, quien le había hecho una entrevista que según Mistral tenía imprecisiones necesarias de rectificar. Luego de corregir los errores considerados por ella graves Mistral señala: "La otra rectificación es de menor cuantía: su servidora hace versos, pero no lleva melena" (citada en Valle 33). La melena era el peinado característico de las flappers, un tipo de mujer moderna que aunque desafiaba las normas de género era sexualizada a nivel visual con sus falda cortas y exceso de maquillaje. Aunque Mistral lo plantea como un error leve, la mención refuerza la oposición tajante entre lo que podría considerarse vanidad, seguimiento de una moda, versus el trabajo creativo de la poeta.

Revista Iberoamericana, Vol. LXXXI, Núm. 250, Enero-Marzo 2015, 161-182 ISSN 0034-9631 (Impreso)

ISSN 2154-4794 (Electrónico) 
por su incompatibilidad con la primera. Esta interferencia identitaria sería visible en su trato e imagen y podría ser la causa que entorpece sus relaciones sociales. De todas formas Mistral no expresa dudas con respecto a la identidad que es central para ella, la intelectual, y no la reniega, sino más bien manifiesta un interés por manejar sus efectos y así funcionar socialmente.

Durante su estadía en la ciudad de Los Andes, Mistral se escribió regularmente con el joven Eugenio Labarca, aspirante a escritor, a quien aconsejaba y con el cual compartía sus juicios críticos y lecturas. En una de estas cartas, en 1916, Mistral hace una evaluación negativa de la historia y el estado actual de la literatura femenina:

No está de más que le diga lo que pienso sobre la literatura femenina en general, sin especializarme en nadie. Hay una montaña de desprestigio y ridículo en Chile echada sobre las mujeres que escribimos. Hubo razón en echarla. Sin exceptuar ni a doña M. Marín del Solar, la mujer en Chile se ha extendido como las feas enredaderas en guías inacabables de poemas tontos, melosos y lagrimosos, galega pura, insipidez lamentable, insufrible gimoteo histérico. Y lo que nos ha perdido es la pata (sic) de Uds., el elogio desatinado de los hombres que no se acuerdan al hacer sus criticas de los versos escritos por tal o cual mujer, sino de sus ojos y de su enamoradizo corazón....Sé que la obra hermosa de una nos prestigiará a todas y cubrirá siquiera en parte, las verguenzas de tanta hojarasca loca y necia (énfasis mío, citada en Alegría 30).

Mistral hace patente su desprecio por la literatura femenina chilena que la antecede, aunque cabe señalar que valoraba a varias precursoras latinoamericanas (Sor Juana, Delmira Agustini). Lo que resulta interesante es que la culpa, según Mistral, no es solo de la mujer que ha escrito malos versos, sino del hombre que al hacer crítica literaria no se acuerda de los versos sino de la imagen, del cuerpo de la mujer. El cambio vendría al escribir buena literatura, pero Mistral no alude a una solución respecto de la actitud del crítico. Podría concluirse, sin embargo, que la escritora que pudiese evitar ser un sujeto atractivo, un objeto de deseo para el hombre, conseguiría un juicio crítico de su obra y no de su persona. Otra estrategia para evitar ser vista sin ser leída, sería entonces para Mistral borrar el atractivo femenino y relacionarse con los hombres en un plano intelectual de igualdad. Eso es lo que ella hace por medio de esta carta a un joven escritor; se separa de ese grupo de mujeres 'histéricas', y hace gala de su conocimiento y capacidad intelectual evitando cualquier rasgo de coquetería o limitándose más bien a una coquetería intelectual con el destinatario.

Esta estrategia y la ansiedad que la motiva está presente en varios epistolarios con escritores e intelectuales de este periodo. ${ }^{20}$ Durante su tiempo en la ciudad de Antofagasta

${ }^{20}$ Un caso emblemático son las cartas con Manuel Magallanes Moure, que aunque muy interesantes en términos de autorepresentación, no las considero en este ensayo porque dan testimonio de una relación sentimental deseada por ambas partes.

Revista Iberoamericana, Vol. LXXXI, Núm. 250, Enero-Marzo 2015, 161-182 ISSN 0034-9631 (Impreso)

ISSN 2154-4794 (Electrónico) 
y con poco más de 20 años de edad, Mistral comienza a escribirse con un maestro y poeta chileno, Antonio Bórquez Solar. En una carta inédita, probablemente la segunda que le envía al poeta (en 1911), Mistral aborda directamente el problema de establecer relaciones con escritores hombres y la necesidad de borrar o trascender cualquier posible tensión sexual para así entablar un intercambio en términos más igualitarios y fraternales. En respuesta a la primera carta que recibe de Bórquez Solar, luego de que ella le escribiera con palabras de gran admiración pero también de enorme deseo de diálogo (le comenta un artículo de él y le manda un artículo de ella) ${ }^{21}$, Mistral aclara: "Le agradezco mui en hondo que mi extraña presentación no le haya sugerido la idea de que busco mas el hombre que el poeta [...] Busco en realidad la comunicación hacia un alma que sé hermosa [...] Así pues olvide Ud. que es una mujer quien le escribe i dispénsele la ternura que le dispensaría a un alma cualquiera" (Gabriela Mistral Papers). Alejar a la mujer de la escritora no pasa porque Mistral reniega de su identidad femenina como rechazo a la definición cultural o la identificación genérica. La escritora hace uso frecuente de su identidad de género tanto en sus poemas como en sus textos en prosa y se apropia y resignifica los estereotipos femeninos que predominan en la época (maternidad, pacifismo, sensibilidad, relación con la naturaleza, entre otros).

En su comunicación con colegas escritores y en su búsqueda de participación en redes intelectuales predominantemente masculinas Mistral separa a la mujer de la escritora porque reconoce que el atractivo sexual de la mujer es un obstáculo para un juicio crítico justo, para un intercambio intelectual profundo y para una participación estable y respetada en un campo literario manejado por hombres. En su carta a Bórquez Solar, luego de que Mistral le aclara que su deseo es conectar con el 'alma bella' del poeta, encontramos una pista de lo que podría haber provocado la necesidad de esta aclaración por parte de la joven escritora: "Me habla Ud. de una fotografía si no es osadía pedirle [...] y si fuera osadía enviarla? Permítame que ese pedido lo haga yo mío, a pesar de que conservo más de una fotografía suya, recortada de revistas" (Gabriela Mistral Papers). Ambos corresponsales reconocen que el pedir una fotografía en este caso puede implicar cierta 'osadía' porque a diferencia de las fotografías que Mistral en otras carta pide a sus amigos, estos jóvenes no se conocen personalmente y dado que Mistral en 1911 aún no era famosa es improbable que Bórquez Solar hubiese visto alguna imagen de la escritora en la prensa. Entonces es la curiosidad que el poeta expresa por

21 La primera carta de Mistral a Bórquez Solar comienza: "Poeta: He aquí a una que le admira silenciosamente hace mucho tiempo, i que hoi ha querido expresárselo". El deseo de contacto y diálogo está presente a lo largo de la carta y tal vez es lo que más tarde Mistral teme que pudiese haber sido interpretado como interés amoroso por su intención de conocer al poeta en persona: "Escribí algunas veces en "La Ley" !Cómo sentí el deseo, cada vez que pasé por la Imprenta, de encontrarle en ella, reconocerlo i hablarlo!" (ortografía original, Gabriela Mistral Papers)

Revista Iberoamericana, Vol. LXXXI, Núm. 250, Enero-Marzo 2015, $161-182$ ISSN 0034-9631 (Impreso)

ISSN 2154-4794 (Electrónico) 
el posible atractivo físico de la joven escritora lo que la llevaría a negarle la fotografía y a aclararle que su intención es establecer un diálogo espiritual e intelectual.

El cuerpo de Mistral, es en sí mismo, un elemento significativo en su performance de género, y por ende en el lugar que ocupa en los esquemas de poder simbólico y cultural. Como señalé anteriormente no eran raros los textos que relacionaban directamente rasgos físicos con cualidades y defectos. La altura inusual de Mistral $(1.80 \mathrm{~cm}$.) y su tipo físico de rasgos duros, como fue descrito, fueron asociados a un carácter imponente y a una autoridad 'natural'. Un ejemplo, es el juicio del ministro chileno Enrique Gajardo quien se relacionó amistosamente con la escritora en Europa: "Gabriela Mistral estaba mejor hecha para oírla que para admirarla por su belleza física. De alta estatura y de porte severo, estaba más bien hecha para mandar que para obedecer" (s/n). En el marco de un sistema cultural patriarcal de estructuras binarias, que la teoría feminista ha puesto en evidencia en tanto relega lo femenino como secundario o no-existente, se es: el que habla o el que escucha, el que manda o obedece, el que crea o el que reproduce, el sujeto o el objeto. El cuerpo de Mistral parece no caber 'naturalmente' en la categoría del subalterno. Sus excesos - altura, discurso- y sus carencias -belleza, sumisióndesarticulan los arbitrarios parámetros que regulan lo masculino y lo femenino tanto a nivel corporal como intelectual. Nuevamente su físico aparece como favorable a su proyecto intelectual, al distinguirla o excluirla de la categoría 'femenina', al negarla como objeto de deseo. Sin embargo, Mistral tiene control y conciencia de esto, pues no hay evidencia de que ella buscara adornar ni 'remediar' este cuerpo. De manera hábil Mistral logra conciliar a nivel visual una imagen que escapa las definiciones tradicionales de género sexual con la imagen poderosa de la madre de América y la 'santa maestra'. ${ }^{22}$

Gabriela Mistral, ya en 1916, seis años antes de publicar su primer libro Desolación parece entender que la imagen femenina estereotípica, en tanto señal de una posición social pasiva y vulnerable al deseo masculino, no es favorable para el éxito literario verdadero. El análisis de sus retratos de esta época da indicios de una puesta en práctica en su imagen de estas ideas. Las fotografías de Mistral muestran a una mujer sin maquillaje, sin adornos, ni joyas, que viste casi siempre ropas oscuras y amplias, que esconden su figura. A partir de sus textos periodísticos y cartas se sabe que juzgaba la moda como una debilidad femenina, sinónimo de lo mundano y opuesto a lo profundo y lo intelectual. ${ }^{23}$ A la imagen de la que dan cuenta las fotografías debe agregarse el performance que Mistral hace en tanto mujer intelectual, del que nos queda un interesantísimo conjunto de

22 Ver la biografía de Virgilio Figueroa, La divina Gabriela y los ensayos de Benjamín Carrión, Santa Gabriela Mistral.

${ }^{23} \mathrm{Al}$ respecto le aconseja a Magallanes Moure acerca de su pequeña hija: "Forma la tuya en el desprecio de las ropas, lo más difícil de formar en una mujer, te lo aseguro. Hazla mirar las cosas en sus profundidades; hazla que aprenda a mirar y a descifrar el rostro de los seres...entre mis peores defectos está el mío de ser extraordinariamente susceptible a la belleza o fealdad de los semblantes" (Manuel 153).

Revista Iberoamericana, Vol. LXXXI, Núm. 250, Enero-Marzo 2015, 161-182 
testimonios de terceros que se relacionaron con ella durante este tiempo. Mistral participa en grupos intelectuales que funcionan a modo de 'fraternidades' en las que ella llega a ser considerada, aunque con ciertas excepciones un 'hermano' más. Al poeta Magallanes Moure le escribe en un principio (antes del comienzo de su relación platónica amorosa) como "Hermano-poeta" o "Poeta" y se despide "fraternalmente". ${ }^{24}$ Su identificación simbólica como madre y hermana figura en mucha de su correspondencia con escritores e intelectuales. El trato fraternal se encuentra temprano en su carrera, y particularmente en un conjunto de cartas entre Mistral y ciertos integrantes de la hermandad artística y teosófica denominada Los Diez. ${ }^{25}$

Mistral desarrolló amistades muy duraderas con hombres destacados de las letras y la política que en varios momentos jugaron un rol determinante en su carrera profesional. Es posible asumir que el trato fraternal contribuyó a la estabilidad de estas relaciones. La inteligencia, el talento poético y la visión única eran cualidades frecuentemente alabadas por quienes han dejado testimonio de su amistad con Mistral. Sin embargo, hay evidencia que confirma que el alejar a la mujer (en tanto objeto sexual) de la escritora resulta en una mayor recepción de Mistral como intelectual. El escritor brasileño Mario de Andrade, que conoció a Mistral en 1927, expone los prejuicios que negaban la idea de la mujer intelectual y cómo Mistral es una 'excepción':

Es la inteligencia femenina más exacta, más sincera que jamás conocí. Algo me desagrada siempre en todas las mujeres que toman la forma de 'intelectuales': algún abuso de sí mismas, algún exceso, algún olvido igualmente falsificador. Fue por eso que me deslumbró Gabriela Mistral. Desprovista ya de los encantos más visibles de una joven, ¡cuánta profundidad, cuánta complejidad había en su encanto de entonces! [....] Pero envuelta siempre en una gracia delicada, que sabía disfrazar su placer en los aires cómodos de la hermana. (citado en Pizarro 106)

Para Andrade la mujer intelectual abusa de sí misma, se falsea, es decir, violenta su naturaleza e identidad, pretendiendo ser algo que no es. Mistral, es según Andrade una inteligencia sincera, desprovista de los encantos de la mujer joven, es decir, no exhibe los rasgos femeninos que la hacen atractiva a los hombres y revela por tanto -sin obstáculos- una profundidad y una inteligencia encantadora. A ojos de Andrade,

${ }_{24}$ Ver cartas 2 y 3 (1914) (Manuel 46-50).

25 Los Diez (1916-1917), fue un grupo de pintores, escultores, músicos, arquitectos y poetas chilenos. En palabras de Manuel Magallanes Moure, miembro del grupo: "Nuestra unión tiene una más firme atadura: nos unen el arte y la amistad. No tenemos obligaciones que llenar ni compromisos que cumplir; nos acerca el placer de estar juntos" (citado en "Los Diez"). Elizabeth Horan da testimonio de estas cartas y del nivel de relación entre Mistral y alguno de sus miembros: "The letters that Gabriela received from theosophists suggest that men in the movement regarded her as a "brother", that is, an honorary man. One lodge member took fraternity to the point of addressing her in the masculine when she wrote to request that she send poem for publication" ("Alternative" 164).

Revista Iberoamericana, Vol. LXXXI, Núm. 250, Enero-Marzo 2015, 161-182 ISSN 0034-9631 (Impreso)

ISSN 2154-4794 (Electrónico) 
Mistral no violeta su identidad de género como otras en tanto su performatividad de la 'feminidad' la aleja de ser un objeto sexual y, por lo tanto, encarna una figura desexualizada como es la hermana.

Mistral revela un elevado nivel de conciencia acerca de la importancia que tiene su propia imagen. Entre 1905 a 1922 se esfuerza por construir una imagen pública que le permita ganar un lugar en el mundo literario y a la vez asegurar un ascenso en su carrera pedagógica. Mistral, aunque en muchos niveles sujeta a las convenciones de su tiempo y defensora de un ideal femenino enfocado en la maternidad, se enfrenta -en el plano visual y performático de su propia imagen-al discurso imperante de la feminidad que imponía un ideal de belleza y apariencia, coherente con una concepción de la mujer como un sujeto pasivo, objeto de la mirada masculina y confinado al espacio doméstico. La no conformación de Mistral con este estereotipo femenino de la época ha sido relacionado directamente al tema de su identidad sexual negándose de esta forma el valor fundacional que tiene el que ella, tanto en su imagen pública como en su vida, resistió un modelo estrecho y opresivo de identidad femenina, al mismo tiempo que logró abrirse paso en una multiplicidad de espacios dominados por los hombres. Su cuerpo de mujer no facilita su entrada en el campo poético e intelectual; hace más bien patente y visible la irrupción, la desestabilización del orden patriarcal que su participación implicaba. En su particular performatividad de género, pone en movimiento una imagen pública funcional a su éxito como escritora e intelectual.

\section{BIBLIOGRAFÍA}

Alegría, Fernando. Genio y figura de Gabriela Mistral. Buenos Aires: Editorial Universitaria, 1966.

Barraza, Isolina. Entrevista con Luis Vera. Gabriela del Elqui. Mistral del mundo: el misterio de una cigarra. Dir. Luis R. Vera. Chile, 2005. DVD.

Bauman, Zygmunt. Legislators and Interpreters: On Modernity, Post-Modernity, and Intellectuals. Ithaca: Cornell UP, 1987.

Betterton, Rosemary. "New Images for the Old: Iconography of the Body". Looking On: Images on Femininity in the Visual Arts and Media. Rosemary Betterton, ed. London: Pandora Press, 1987.

Butler, Judith. Gender Trouble: Feminism and the Subversion of Identity. New York: Routledge, 1990.

Bodies that Matter On the Discursive Meanings of Sex. New York: Routledge, 1993.

Carrión, Benjamín. Santa Gabriela Mistral; ensayos. Quito: Editorial Casa de la Cultura Ecuatoriana, 1956.

Délano, Luis Enrique. “Gabriela Mistral, la voz de la poesía desnuda". Cuadernos (Fundación Pablo Neruda) 22 (1995): 8-23.

Diamond, Elin. Performance and Cultural Politics. London: Routledge, 1996.

Revista Iberoamericana, Vol. LXXXI, Núm. 250, Enero-Marzo 2015, 161-182 ISSN 0034-9631 (Impreso)

ISSN 2154-4794 (Electrónico) 
Diccionario de la Real Academia Española. “Imagen”. Vigésima primera edición. 1992. Echeverría, Inés “Gabriela Mistral”. Recopilación de la obra Mistraliana: 1902-1922.

Recopilación e introducción de Pedro Pablo Zegers. Santiago: RIL, 2002. 523-525.

Figueroa, Virgilio. La divina Gabriela. Santiago de Chile: Impr. El Esfuerzo, 1933.

Fiol-Matta, Licia. A Queer Mother for the Nation: The State and Gabriela Mistral.

Minneapolis: U of Minnesota P, 2002.

Gabriela Mistral Papers, Benson Latin American Collection, General Libraries, the University of Texas at Austin.

Gajardo, Enrique. "Gabriela Mistral”. El Mercurio (18 de junio de 1989).

García-Huidobro, Cecilia. Moneda dura: Gabriela Mistral por ella misma. Santiago: Catalonia, 2005.

Guillén, Palma. “Prólogo". Lecturas para Mujeres. Gabriela Mistral, ed. México D.F: Porrúa, 1997.

Henríquez Ureña, Pedro. Literary Currents in Hispanic America. Cambridge: Harvard UP, 1946.

Horan, Elizabeth. "Santa Maestra Muerta: Body and Nation in Portraits of Gabriela Mistral." Taller de Letras 25 (1997): 21-43.

“Alternative Identities of Gabriel(a) Mistral 1906-1920". Reading and Writing in the Ambiente. Susana Chávez-Silverman and Librada Hernández, eds. Madison: U of Wisconsin P, 2000. 147-77.

Hurtado, María de la Luz. "La performance de los Juegos Florales de 1914 y la inadecuada presencia de Gabriela Mistral en ellos". Revista Chilena de Literatura 72 (2008): 163-191.

“Los Diez (1916-1917)". Presentación. memoriachilena.cl. DIBAM (Dirección de Bibliotecas, Archivos y Museos). 20 diciembre 2011. <http://www.memoriachilena. cl/temas/index.asp?id_ut=losdiez(1916-1917)>.

Ludmer, Josefina. “Tretas del débil". La sartén por el mango. Patricia González y Eliana Ortega, eds. Río Piedras: Ediciones Huracán, 1984.

Michelet, Ana. "Justicia al mérito". Recopilación de la obra Mistraliana: 1902-1922. Recopilación e introducción de Pedro Pablo Zegers. Santiago: RIL, 2002. 181-182.

Mistral, Gabriela. Cartas de amor de Gabriela Mistral. Recopilación e introducción de Sergio Fernández Larraín. Santiago, Chile: Editorial Andrés Bello, 1978.

Recopilación de la obra Mistraliana: 1902-1922. Recopilación e introducción de Pedro Pablo Zegers. Santiago: RIL, 2002.

Mistral, Gabriela y Manuel Magallanes Moure. Manuel, en los labios por mucho tiempo: epistolario entre Lucila Godoy Alcayaga y Manuel Magallanes Moure. María Ester Martínez Sanz y Luis Vargas Saavedra, eds. Santiago, Chile: Ediciones Universidad Católica de Chile, 2005.

Mitchell, W.J.T. Teoría de la imagen. Madrid: Akal Ediciones Sa, 2009. Iconology: Image, Text, Ideology. Chicago: U of Chicago P, 1986.

Revista Iberoamericana, Vol. LXXXI, Núm. 250, Enero-Marzo 2015, $161-182$ ISSN 0034-9631 (Impreso)

ISSN 2154-4794 (Electrónico) 
Neruda, Pablo. Confieso que he vivido. Memorias. Barcelona: Seix Barral, 1984.

Olea, Raquel "El lugar de Gabriela Mistral" y "Otra lectura de 'La otra". Una Palabra Cómplice: Encuentro con Gabriela Mistral. Raquel Olea y Soledad Fariña, eds. Chile: Corporación de Desarrollo de la Mujer La Morada, 1990.

Ossandón, Carlos y Eduardo Santa Cruz. El estallido de las formas: Chile en los albores de la "cultura de masas". Santiago: LOM / ARCIS, 2005.

Pizarro, Ana. Gabriela Mistral: El proyecto de Lucila. Santiago: LOM, 2005.

Rojo Grinor, Rojo. Dirán que está en la gloria. Santiago de Chile: Fondo de Cultura Económica, 1997.

Soto Ayala, Carlos. "Lucila Godoy Alcayaga". Literatura Coquimbana. Santiago: Imprenta Francia, 1908. 100-104.

Teitelboim, Volodia. Gabriela Mistral pública y secreta. Truenos y silencios en la vida del primer Nobel latinoamericano. Santiago: Ed. Sudamericana, 1996.

Unruh, Vicky. Performing Women and Modern Literary Culture in Latin America: Intervening Acts. Austin: U of Texas P, 2006.

Valle, Rafael Heliodoro. “Alabanza de Gabriela Mistral”. Gabriela Mistral 1889-1957. Washington D.C.: Pan American Union, 1958. 